\title{
The research on the classification method of high water-cut well group in $Y$ block
}

\author{
Y u X iaoyuan ${ }^{1}$ \\ ${ }^{1}$ Geological B rigade of the first oil Production Plant of Daqing Oilfield CO. LTD
}

\begin{abstract}
Y block has entered the ultra-high water cut stage of production, and the water cut of oil wells is generally higher than $90 \%$. B efore polymer flooding, water cut continues to rise. High-water-bearing wells in the injected area are characterized by difficulty in effectiveness and low water cut decline, which seriously affects the overall development effect of the area. In this paper, the high water-bearing wells are divided into four categories by the parameter index of the number of layers in the high water-bearing channels before polymer flooding.Through the splitstream curve and the phase permeability curve, the permeability and oil saturation data under the condition of $98 \%$ water content were selected for fitting, and the critical oil saturation formula was obtained.The ratio between the oil saturation and the critical oil saturation is calculated by numerical simulation, and the discriminant standard of the dominant seepage channel with high water content is established.Compared with previous remaining oil saturation field identification methods, changed the method according to the conventional ideas of remaining oil saturation evaluation of water and residual oil, through the analysis of reservoir permeability parameters for the current development under the condition of the target reservoir quantitative identification of the cause of high water cut, to cause high containing water wells and reservoir high water cut oilfield management work provide quantitative analysis and objective guidance.
\end{abstract}

\section{Introduce}

Y block began production in 1960, after basic well pattern waterflood recovery stage, encryption, well pattern adjustment stage and after polymer flooding stage, both at the late high water cut exploitation stage, as the well pattern infilling and injected water wash for a long time, reservoir plane and interlamination layers, increasingly prominent, the invalid water cycle, remaining oil potential in difficult. ${ }^{[1-2]}$ Therefore, this article in view of the $\mathrm{Y}$ block oil reservoir characteristics, production in the block dynamic and static data, through the analysis of the causes of the formation of high containing water wells, adjust high water-content numerical simulation model is set up, clearly different types of high containing water layers in the plane, interlayer and adjustment mechanism, improve the utilization rate of polymer control inefficient injection water circulation, so as to improve the effect of overall development. ${ }^{[3]}$

Statistical analysis in this paper, the concrete research content is as follows: polymer injection after water drop and unit effective thickness increased quantity dynamic and static parameters, such as oil, high containing water well dynamic and static database is established.By using the phase permeability curve and the fractional flow rate curve, the critical oil saturation was obtained by fitting the permeability and oil saturation point, and then the ratio of the critical oil saturation to the critical oil saturation was established to establish the criterion for determining the dominant seepage channel of invalid water injection cycle with high water cut ${ }^{[4]}$.The high water-cut channels of 89 wells were calculated and identified, and 89 high water-cut wells were divided into four categories.

\section{Methods}

\subsection{Determination of waterflooding high water- cut passage boundary}

(1) Formula of shunt volume

Critical oil saturation, i.e. oil saturation when water content is $98 \%$; The dominant seepage channel of water flooding with high water cut is referred to as the high water cut channel, and the equation of shunt volume is formula (2-1).

$$
f_{w}=\frac{1}{1+\left(\frac{K_{r o}}{K_{r w}}\right)\left(\frac{\mu_{w}}{\mu_{0}}\right)} \ldots \ldots \ldots \ldots . .(2-1) .
$$

Among them: $\mathrm{f}_{w}$ is the moisture content, small number; $\mu_{\mathrm{o}}$ is oil phase viscosity, $\mathrm{mPa} \cdot \mathrm{S} ; \mu_{\mathrm{w}}$ is the water phase viscosity, $\mathrm{mPa} \cdot \mathrm{S} ; K$.ro is oil relative permeability, decimal; $K$.rw is water relative permeability, decimal. 
By using the fractional flow equation and combining with the relative permeability curve, 10 groups of oil saturation and permeability data at different water cut levels were selected (Fig 2-1), and then the relation curve between permeability at different water cut levels and critical oil saturation was obtained by fitting.Therefore, in the case of water flooding in Y block, the critical oil saturation in the formation of invalid water injection cycle can be calculated by combining the fractional flow rate curve with the phase permeability curve.

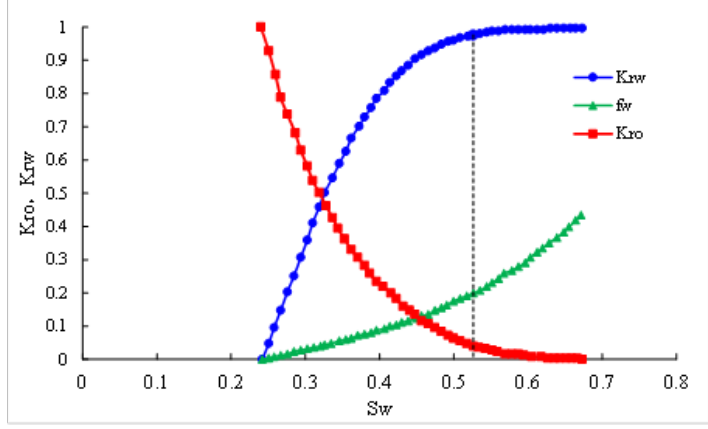

Fig. 2-1 Distributary flow and relative permeability

curve

The permeability was $0.1 \mu \mathrm{m}^{2}, 0.5 \mu \mathrm{m}^{2}$ and $1 \mu \mathrm{m}^{2}$, respectively, and the critical oil saturation of Y block was $39 \%, 44.7 \%$ and $46.1 \%$, respectively, when the water injection cycle was formed. When polymer displacement was carried out in $\mathrm{Y}$ block, the permeability was $0.1 \mu \mathrm{m}^{2} 0.5 \mu \mathrm{m}^{2}$ and $1 \mu \mathrm{m}^{2}$ respectively. When water injection invalid cycle was formed in the reservoir, the critical oil.The higher the reservoir permeability is, the higher the oil saturation is when the ineffective water injection cycle is formed (water content is $98 \%$ ), that is, the more easily the ineffective water circulation channel is formed in the high-permeability layer. saturation was $30.25 \%, 37.5 \%$ and $39.3 \%$, respectively

(2) Formula of critical oil saturation

The critical (98\% moisture content) oil saturation formula under water flooding condition is obtained by means of fractional flow rate curve and phase permeability curve according to oil saturation and permeability data, and then fitting, as shown in equation $(2-2)$.

$$
S_{w o}=3.6997 \times \ln P+24.737
$$

(3) Discriminant formula of high water cut channel

The oil saturation $\mathrm{S}_{\mathrm{ro}}$ at different permeability levels was calculated by numerical simulation, and the critical oil saturation $\mathrm{S}_{\mathrm{wo}}$ under the permeability condition, and the discriminant formula of high water cut channel is established. In the actual development process, due to the influence of factors such as production system, development status and geological conditions, there are differences in reservoir development, resulting in different oil saturation in each grid and different swept conditions. When the moisture content is $98 \%$, the highwater-cut channel coefficient is 1 . Due to reservoir heterogeneity, the ratio of high water-cut channel coefficient is different. When the high water-cut channel coefficient is less than 1 , the development condition is better than the pre-period, and the swept volume of injected water in this area increases, and the high watercut channel will be formed. The discriminative formula of high water cut channel under water flooding condition is shown in equation (2-3).

$$
R_{w o}=\frac{S_{r o}}{S_{w o}}
$$

In the formula: unit $\mathrm{P}$ is permeability, $10^{-3} \mu \mathrm{m}^{2} ; R_{\mathrm{wo}}$ is the high water cut channel coefficient, that is, the ratio between the remaining oil saturation calculated by mathematical model and the critical oil saturation under the condition of water flooding, decimal; $S_{\mathrm{wo}}$ is the critical oil saturation, $\% ; S_{\mathrm{ro}}$ is the oil saturation calculated by numerical simulation under water flooding condition, $\%$.

(4) Discriminant boundary value of high water-cut channel

According to the water content values of $99 \%, 98 \%$ and $90 \%$, the critical oil saturation is calculated by the critical oil saturation formula, Then the oil saturation in the grid is calculated by numerical simulation, and the boundary value of the water-bearing channel is obtained by the ratio of the critical oil saturation to the critical oil saturation. Therefore, according to the moisture content value of $99 \%, 98 \%$ and $90 \%$, the corresponding boundary value of water-bearing channel is $0.8,1.0$ and 1.2 respectively.

Through the moisture content value, the criterion for determining the high water-cut channel of water flooding is: when $\mathrm{R}_{\text {wo }}<0.8$, the water-cut channel is identified as an ultra-high water-cut channel, and the corresponding moisture content range is $\mathrm{F}_{\mathrm{w}}>99 \%$; When $0.8<\mathrm{R}$ wo $<1$, the water-cut channel is identified as a high-cut channel, and the corresponding moisture content range is $98 \%<\mathrm{F}_{\text {w }}<99 \%$; When $1<\mathrm{R}_{\text {wo }}<1.2$, the water-cut channel is judged to be medium and high water-cut channel, and the corresponding water-cut channel is $90 \%<\mathrm{f}_{\mathrm{w}}<98 \%$; When $\mathrm{R}_{\text {wo }}>1.2$, the water-cut channel is identified as medium and low water-cut channel, and the corresponding moisture content is $\mathrm{f}_{\mathrm{w}}<90 \%$, as shown in table 2-1.

Table 2-1 Discriminant criteria of water flooding high water cut channel

\begin{tabular}{|c|c|c|}
\hline $\mathrm{R}_{\text {wo }}$ & Channel type & moisture content (\%) \\
\hline$<0.8$ & $\begin{array}{c}\text { Ultra high water cut } \\
\text { channel }\end{array}$ & $>99$ \\
\hline $0.8 \sim 1.0$ & $\begin{array}{c}\text { High water cut } \\
\text { channel }\end{array}$ & $99 \sim 98$ \\
\hline $1.0 \sim 1.2$ & $\begin{array}{c}\text { M edium and high } \\
\text { water cut channels }\end{array}$ & 980 \\
\hline$>1.2$ & $\begin{array}{c}\text { M edium and low } \\
\text { water cut channels }\end{array}$ & $<90$ \\
\hline
\end{tabular}


The high water-cut channel coefficient of 789,700 The high water-cut channel coefficient of 789,700 grids in the water flooding model was calculated and discriminated by using the high water-cut channel criterion. The water cut channel coefficient of each layer of 89 high water-cut wells was counted and formatted to obtain the high water-cut channel coefficient charts of sedimentation units S22 and S28. It can be found from the figure that there are a large number of high-water-cut channels near the injection wells in a single infill pattern, and the water content is more than $98 \%$. There are a large number of medium and high water cut channels around the injection wells with secondary infill pattern, with water cut generally between $95 \%$ and $98 \%$ (Fig 22). Calculating coefficient of high water cut channel, therefore, to establish high water-content channel level, find out high containing water Wells and foundation, the position of the secondary infill well net injection wells, and about 89 small layers of high water cut wells, remaining oil saturation, effective thickness, permeability of formation coefficient, connecting relation, injection-production well spacing, high water cut for statistical parameters such as coefficient of channel, so that the next step analysis of the causes of the formation of high containing water wells. Among them, the number of high-water-cut channels is greater than 1.6, and the corresponding moisture content is less than $85 \%$. The high water-cut channel coefficient is between 1.2 and 1.6, and the corresponding moisture content ranges from $85 \%$ to $90 \%$.

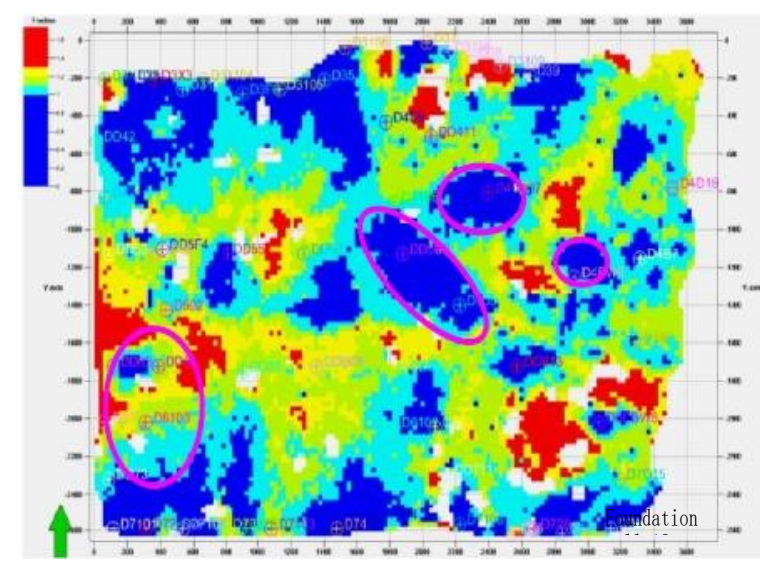

Fig 2-2 Schematic diagram of high water cut channel

\subsection{Classification of high water-cut channels in water flooding}

According to the situation of 89 wells with high content, it is necessary to classify them to facilitate the treatment and adjustment of each well group in the later stage. The proportion of high water-cut channel layers is the ratio between the number of high water-cut channels in water flooding and the number of ejected layers. The larger the ratio is, the more the high water-cut channels are and the easier it is to form high water-cut.The proportion of high water-cut channel layers was classified into four categories, and 89 high water-cut wells were divided into four categories. As the proportion of high water-cut channel layers increased, the average effective thickness of single channel on the whole increased.Among them, there are fewer channels in one type of high-water-cut well group and more channels in the third and fourth type of high-water-cut well group (Table2-2).

Table 2-2 Statistical table of different types of high-water-cut groups

\begin{tabular}{|c|c|c|c|c|}
\hline type & $\begin{array}{c}\text { High water cut } \\
\text { channelThe } \\
\text { layer number of } \\
\text { proportion(\%) }\end{array}$ & $\begin{array}{c}\text { Well } \\
\text { number }\end{array}$ & permeability $\left(\mu \mathrm{m}^{2}\right)$ & $\begin{array}{c}\text { Effective } \\
\text { thickness }(\mathrm{m})\end{array}$ \\
\hline $\begin{array}{c}\text { type } \\
\text { I }\end{array}$ & $0<\mathrm{x}<20$ & 19 & 0.3014 & 37.5 \\
\hline $\begin{array}{c}\text { type } \\
\text { II }\end{array}$ & $20<\mathrm{x}<35$ & 26 & 0.3075 & 62.3 \\
\hline $\begin{array}{c}\text { type } \\
\text { III }\end{array}$ & $35<\mathrm{x}<70$ & 22 & 0.3124 & 181.1 \\
\hline $\begin{array}{c}\text { type } \\
\text { IV }\end{array}$ & $\mathrm{x}>70$ & 22 & 0.3046 & 241.5 \\
\hline
\end{tabular}

Among the four types of high-water-cut well groups, one type of high-water-cut well group has a low proportion of channel beds and few high-water-cut Wells. The average cumulative oil production per unit thickness of a single well is $341.21 \mathrm{~m}^{3}$, which is significantly higher than the other three types of high-water-cut well groups, with relatively strong production capacity. The third and fourth types of high-water-cut well groups have more channels.According to the characteristics of high water-cut channels in different types of Wells, theoretical basis is provided for the treatment of different types of high water-cut wells in the later stage.

The number of high-water-cut channels, total perforation zone and the proportion of high-water-cut channel zone in each type of high-water-cut well group were counted, so as to facilitate the next study on the genesis and adjustment mechanism of high-water-cut well group.

Through the single factor analysis of permeability variation coefficient, low permeability layer thickness ratio, the effective thickness is less than one meter, multidirectional connected ratio statistics, average water cut before the polymer injection parameters, such as research on the effect of high water cut well group classification, the results show that the various factors influencing regularity is not obvious, water drive causes of high water cut well group is caused by many factors. The average water cut before injection has a great influence on the well group classification, which should be taken into account.one-way anova is used to study the relationship between classified data and quantitative data, that is, to study whether there is a significant difference between 10 factors, such as well distance, effective thickness, layer proportion of mainstream line, coefficient of permeability variation and formation coefficient, and layer proportion of high-water-cut channel.Through the study of this method, it is analyzed that the five factors, i.e., the spacing of wells, the proportion of layers along the main stream, the 
coefficient of permeability variation, the average moisture content before injection and the proportion of low permeability thickness, have significant influences on the classification of the four types of high-water-cut well groups in water flooding, and different types of high-water-cut well groups can be identified.

The high-water-cut well group is divided into four categories by the five indexes of well spacing, the proportion of the main flow line, the average water content before injection, the coefficient of permeability variation and the proportion of the thickness of the lowpermeability layer.The classification accuracy of this block is over $95 \%$, with a high accuracy. The classification boundary is shown in table 2-3 below.

Table 2-3 Statistical analysis table of classification boundaries of different types of high-water-cut well groups

\begin{tabular}{|c|c|c|c|c|c|}
\hline type & $\begin{array}{l}\text { Well spacing } \\
(\mathrm{m})\end{array}$ & $\begin{array}{l}\text { The proportion of the } \\
\text { main line }\end{array}$ & $\begin{array}{l}\text { A verage moisture content } \\
\text { before injection }\end{array}$ & $\begin{array}{c}\text { Coefficient of permeability } \\
\text { variation }\end{array}$ & $\begin{array}{l}\text { Low permeability thickness } \\
\text { ratio column }\end{array}$ \\
\hline type & \multirow{3}{*}{ M ore than 200} & \multirow{2}{*}{\multicolumn{2}{|c|}{$\begin{array}{l}\text { The proportion of the main line layer is less than } 83 \% \text { or } \\
\text { the average moisture content before polymer injection is } \\
\text { less than } 97 \%\end{array}$}} & Less than $56 \%$ & Less than $22 \%$ \\
\hline $\begin{array}{l}\text { type } \\
\text { II }\end{array}$ & & & & \multicolumn{2}{|c|}{$\begin{array}{l}\text { The permeability variation coefficient is greater than } 55 \% \\
\text { or the thickness ratio of low permeability layer is greater } \\
\text { than } 22 \%\end{array}$} \\
\hline $\begin{array}{l}\text { type } \\
\text { III }\end{array}$ & & M ore than $83 \%$ & M ore than $97 \%$ & & - \\
\hline $\begin{array}{l}\text { type } \\
\text { IV }\end{array}$ & Less than 200 & & & - & \\
\hline
\end{tabular}

\section{Conclusion}

The research on the classification methods of the highwater-cut well group provides technical support for the genesis of the high-water-cut well group in the later stage. Various types of high-water-cut well groups are greatly affected by well spacing. The characteristics of different types of high-water-cut well groups are as follows:

Characteristics of type I high-water-cut well group: well spacing is more than $200 \mathrm{~m}$, the thickness ratio of low-permeability layer is less than $22 \%$, and permeability variation coefficient is less than 0.56 . It is almost not in the historical mainstream line, with weak heterogeneity, fewer high-water-cut channels and lower overall moisture content phase pairs. The accuracy of identifying type I high-water-cut well is $92 \%$.

Characteristics of type II high water-bearing well group: well spacing $>200 \mathrm{~m}$; permeability variation coefficient $>0.56$; thickness ratio of low permeability layer $>22 \%$; relatively strong heterogeneity; accuracy of identifying type II high water-bearing well in this block is $95 \%$;

The characteristics of type III of high-water-cut well groups are as follows: the spacing of Wells is over $200 \mathrm{~m}$; the proportion of layers in the mainstream line is over $83 \%$; the average moisture content before injection is over $97 \%$; there are many channels for high-water-cut; the perforation position of each layer is mainly on the mainstream line; the overall moisture content is relatively high.

Characteristics of type IV of high-water-cut well group: well spacing is less than 200 meters, the number of high-water-cut channels is large, the moisture content is high, and the identification accuracy of type IV highwater-cut wells is $95 \%$.

\section{Reference}

1. Guo-Zhong Z, Wei S, X in H E. Reservoir simulation model based on stratified water injection and its application[J]. journal of northeast petroleum university, 2012

2. Flory P J. Principles of Polymer Chemistry[M ]. N ew York: Cornell U niversity Press,1953: 125-129.

3. Zhenhai J. Identification of Thin Interlayer and Potential Tapping of Residual Oil in Channel Sand B odies[J] ]. xinjiang petroleum geology, 2018.

4. X ia Huifen, Ju Ye, K ong Fanshun.Effect of Elastic Behavior of HPAM Solutions on Displacement Efficiency under Mixed Wettability Conditions[C],SPE 90234-M S,2004. 